\title{
School-type differences in e-cigarette use and its correlates among Chinese adolescents
}

\author{
Jingfen $\mathrm{Zhu}^{1^{*}}$, Jiahui $\mathrm{Li}^{i^{*}}$, Gang $\mathrm{Xu^{1 }}$, Jinming $\mathrm{Yu}^{2}$, Qian Wang ${ }^{1 *}$, Yaping $\mathrm{He}^{1 \#}$
}

\begin{abstract}
INTRODUCTION Studies examining e-cigarette use among adolescents in Shanghai, China, have focused largely on middle school students. Given the vast differences between vocational and traditional schools, we aimed to explore school-type differences in e-cigarette use and correlates among adolescents in Shanghai.

METHODS The study was conducted in September 2017 through multistage and stratified cluster random sampling, which consisted of 10699 adolescents aged 13-17 years attending traditional and vocational schools in Shanghai. Descriptive statistics and multivariate logistic regressions were conducted to assess the weighted prevalence and correlates of ever e-cigarette use stratified by school type.

RESULTS The weighted prevalence of e-cigarette use was $5.21 \%$ among all respondents. Although e-cigarette use was more prevalent among students attending vocational schools $(\mathrm{p}<0.001)$, its correlates were similar across both school types. Among vocational school students, ever tobacco use (OR=3.10; 95\% CI: 2.36-4.08) was the most significant correlate, followed by having most friends as smokers ( $\mathrm{OR}=2.97$; 95\% CI: $1.84-4.81)$ and having morning cravings $(\mathrm{OR}=1.90 ; 95 \%$ CI: 1.64-2.20). Among traditional school students, having most friends as smokers ( $\mathrm{OR}=4.87$; $95 \% \mathrm{CI}: 2.78-8.54)$ and ever tobacco use ( $\mathrm{OR}=3.78$; 95\% CI: 2.68-5.34) were the most significant correlates, followed by knowledge of pro-tobacco advertisements ( $\mathrm{OR}=2.12$; 95\% CI: $1.54-2.91)$.

CONCLUSIONS Joint efforts from the national, school and family levels are needed to control e-cigarette use among adolescents in China, and such efforts should be tailored to address differences in school characteristics.
\end{abstract}

\begin{tabular}{l} 
AFFILIATION \\
1 College of Public Health, \\
Shanghai Jiao Tong University \\
School of Medicine, Shanghai, \\
China \\
2 School of Public Health, \\
Fudan University, Shanghai, \\
China \\
*Contributed equally \\
"Co-correspondence authors \\
CORRESPONDENCE T0 \\
Qian Wang. College of \\
Public Health, Shanghai Jiao \\
Tong University School of \\
Medicine, 227 S Chongqing \\
Road, Shanghai 200025, \\
China. E-mail: \\
qianwang1@outlook.com. \\
Yaping He. College of Public \\
Health, Shanghai Jiao Tong \\
University School of Medicine, \\
227 S Chongqing Road, \\
Shanghai 200025, China. \\
E-mail: hypcyr@sina.com \\
KEYw0RDS \\
e-cigarettes, adolescents, \\
China, vocational schools \\
\hline Received: 23 January 2020 \\
Revised: 26 February 2020 \\
Accepted: 3 March 2020 \\
\end{tabular}

https://doi.org/10.18332/tid/118721

\section{INTRODUCTION}

When e-cigarettes entered the market in the early 2000s, they were often advertised as healthier alternatives to traditional cigarettes or as smoking cessation aids ${ }^{1}$. However, the impact of e-cigarettes on smoking cessation has been found to be inconsistent ${ }^{2}$. Some studies found smokers used e-cigarettes to help them quit smoking ${ }^{3}$, while others found no benefit in using e-cigarettes to quit smoking, or even found a detrimental effect among smokers that used e-cigarettes ${ }^{4}$.
E-cigarette use has increasingly gained popularity among adolescents. A nationally representative survey in the US reported a significant increase in current use of e-cigarettes among middle school $(0.6 \%$ to $5.3 \%)$ and high school students (1.5\% to $16.0 \%)$ from 2011 to $2015^{5}$. A British survey found that about a tenth to a fifth of those aged 11-16 years had tried e-cigarettes 6 . In Canada, about $20 \%$ of youth aged 15-19 years reported 'ever tried' e-cigarettes, of whom $14 \%$ were non-smokers ${ }^{7}$. In South Korea, about 
9-10\% of adolescents were found to be e-cigarette users, of whom $75-76 \%$ also used tobacco ${ }^{8}$. The prevalence of e-cigarette use was also high among youth in Taiwan, as a survey showed e-cigarette use was particularly common among those aged $15-24$ years who were current $(49-52 \%)$ or former (22-39\%) smokers ${ }^{9}$. In Hong Kong, about $1.1 \%$ of secondary school students (mean age $=14.8 \pm 1.9$ years) used e-cigarettes currently, and $11.7 \%$ of e-cigarette users never smoked cigarettes ${ }^{1}$. Even though mainland China is among the world's largest and major producers of e-cigarettes ${ }^{10}$, and over $90 \%$ of the world's e-cigarettes come from cities such as Shenzhen ${ }^{1}$, studies on e-cigarette use among Chinese adolescents are few. A recent national survey found the prevalence of e-cigarette use and awareness to be $1.2 \%$ and $45.0 \%$, respectively, among middle school students in China ${ }^{11}$.

A number of studies have examined factors associated with e-cigarette use among adolescents. E-cigarette use has been strongly linked to smoking and susceptibility to smoking ${ }^{7}$. A study found curiosity was the most commonly cited reason among less frequent e-cigarette users, while the desire to quit smoking and the opportunity for indoor use were the most commonly cited reasons among more frequent users ${ }^{11}$. A national survey conducted among middle school students in China found e-cigarette awareness and use were associated with: cigarette smoking, having parents or close friends who smoke, exposure to pro-tobacco advertising and anti-tobacco messages, having a positive attitude to smoking, and having more pocket money ${ }^{12}$. However, this survey did not include high school students. There is evidence suggesting that e-cigarette use may be more prevalent among high school students. For example, in 2014, the rate of e-cigarette use was $3.9 \%$ among middle school students but was $13.4 \%$ among high school students in the $\mathrm{US}^{13}$. Moreover, in 2015, this rate increased to $5.3 \%$ among middle school students and $16.0 \%$ among high school students ${ }^{14}$.

In China, compared with traditional high schools, vocational high schools often have low academic requirements. Students attending vocational high schools tend to receive less parental monitoring ${ }^{15}$. These differences may contribute to more health risk behaviors among vocational school students.

The purpose of our study was to explore school-type differences in e-cigarette use and correlates among adolescents in Shanghai. As the largest metropolitan area in China, Shanghai is home to 34 million people. We examined students' use of e-cigarettes, its associations with tobacco use, morning craving, parents' and friends' smoking, exposure to pro- and anti-tobacco advertisements and to secondhand smoking (SHS), with the hope that better policies will be developed for regulating e-cigarette use among youth.

\section{METHODS}

\section{Sample}

This cross-sectional study was conducted in September 2017 through multistage and stratified cluster random sampling. Participants were adolescents attending traditional middle schools and high schools, and also from vocational high schools, in Shanghai. Sixteen districts in Shanghai were stratified into central urban and non-central urban areas, and four districts were randomly selected, with Huangpu and Putuo as central urban areas, and Minhang and Jiading as non-central urban areas. All schools in these four districts were further stratified into middle schools, traditional high schools, and vocational high schools. From these, a total of 33 schools were randomly selected, with one vocational school chosen randomly from each district. A total of 12278 students participated in the study, with 10699 $(87.1 \%)$ returning questionnaires with all questions used in the analysis completed.

Participation in this study was voluntary. Written informed consent was obtained from all students, their guardians and school organizers before enrollment, and covered objectives, procedures, potential risks and benefits of the study. The study was approved by the Ethics Committee of the School of Public Health, Shanghai Jiao Tong University.

\section{Measures}

Use of electronic cigarettes was the outcome variable of interest and was measured by the question: 'Have you tried electronic cigarettes (even one puff)?'; with answer options 'yes/no'.

Morning craving was an independent variable and measured by the question: 'Do you smoke soon or crave for a cigarette upon waking up in the morning?'; with answer options 'I don't smoke', 'I haven't smoked 
for a long time', 'No, I don't crave for a cigarette in the morning', 'Yes, sometimes', and 'Yes, often'. This variable was treated as a continuous variable.

Awareness of anti- and pro-tobacco advertisements was assessed separately by asking respondents if they had seen or heard of anti- or pro-tobacco advertisements from four channels in the past 30 days: traditional media (TV, films, broadcasting, newspaper, billboards); digital media (cell phones, computers/ laptops, websites); mobile digital billboards on buses or subways; community activities; sports events, concerts, exhibitions, and community gatherings. Response options were: 1) 'I don't have the opportunity to see such advertisement', 2) 'often (four times and above)', 3 ) 'sometimes (one to three times)', and 4) 'No, I haven't seen such advertisement'. Those who chose 2) and 3) were considered having awareness of anti- or pro-tobacco advertisements, and those choosing 1) and 4) were considered as not having awareness of anti- or pro-tobacco advertisements.

Ever tobacco use was assessed by: 'Have you ever tried cigarette smoking (even one or two puffs)?'. Participants were grouped into those who answered 'yes' versus 'no'.

Parents' smoking status was measured by two questions: 'Does your father smoke?' and 'Does your mother smoke?'. Answer options were: 1) 'No', 2) 'Sometimes', 3) 'Often', and 4) 'I don't know'. Participants were grouped into three categories based on their responses, those who answered 2) and 3) to both questions were considered as having both parents as smokers, while those who answered 2) and 3) to either one of the two questions were considered as having one parent as a smoker. Those who answered 1) and 4) to both questions were considered as having parents who were non-smokers.

Friends' smoking status was measured by: 'Do you have friends that smoke?'. Answer options were: 1) No, 2) Some of them, 3) Majority of them, and 4) All of them; these were then grouped into three categories with 3) and 4) combined.

Secondhand smoke (SHS) was measured by past 7-day exposure to SHS at home, in indoor public places (shops, restaurants, movie theatres, train stations etc.), and at outdoor areas (parks, playgrounds, sidewalks etc.). Response options were: 1) 0 days, 2) 1-2 days, 3) 3-4 days, 4) 5-6 days, and 5) 7 days. Those answering 0 days or 1-2 days to all three sources of exposure to SHS were treated as the group with low exposure, and those answering 3-4 days or above to any of the three sources of exposure to SHS were treated as the group with high exposure.

Demographic covariates included: age (11-13; 14-15; and 16-17 years), gender, residence (local, non-local), grade point average (GPA) (continuous), type of school (middle, high, vocational high school), and monthly allowance (continuous).

\section{Data analysis}

We used Statistical Package for the Social Sciences version 22.0 for all statistical analyses. Data were weighted based on selection probability of districts, the number of schools in each district, and the number of students in each school. Sample characteristics and e-cigarette use characteristics were summarized using weighted percentages and confidence intervals. Odds ratios (ORs) with 95\% confidence intervals (CIs) were calculated to examine overall, as well as school-specific associations between each independent variable and e-cigarette use. For each school type, adjusted odds ratios (AORs) with their 95\% confidence intervals (CIs) of the associations between e-cigarette use and its correlates were estimated by multivariate logistic regression models, which could account for several confounding variables simultaneously. A $p<0.05$ was considered statistically significant.

\section{RESULTS}

\section{Sample characteristics}

The overall sample consisted of 10699 students (mean age $=13.8 \pm 2.1$ years) attending middle school $(62.1 \%)$, high school $(23.9 \%)$, or vocational high school (14.0\%), in Shanghai (Table 1).

The total prevalence of e-cigarette use was $5.2 \%$. Prevalence was significantly higher among adolescents aged $16-17$ years $(10.1 \%)$, males $(7.1 \%)$, non-local residents $(6.4 \%)$, attending vocational high schools (14.0\%), had ever tried using tobacco (29.7\%), had both parents $(17.2 \%)$ or most friends $(47.3 \%)$ as smokers, had seen pro-tobacco advertisements (6.5\%) or not seen anti-tobacco advertisements $(8.7 \%)$, and were highly exposed to SHS $(8.2 \%)$.

\section{Logistic regressions}

In the unadjusted model (Table 2), the associations between ever use of e-cigarettes and all correlates 
Table 1. Characteristics distribution and ever use of e-cigarettes among adolescents, Shanghai, China, September $2017(\mathrm{~N}=10669)$

\begin{tabular}{|c|c|c|c|c|}
\hline \multirow[t]{2}{*}{ Characteristics } & \multicolumn{2}{|c|}{ Orerall } & \multicolumn{2}{|c|}{ Ever use of e cigarettes } \\
\hline & n & $\begin{array}{l}\text { Weighted \% } \\
95 \% \text { CI }\end{array}$ & n & $\begin{array}{c}\text { Weighted \% } \\
95 \% \text { CI }\end{array}$ \\
\hline Overall & 10669 & & 695 & $5.2(4.8-5.6)$ \\
\hline \multicolumn{5}{|l|}{ Age (years) } \\
\hline $11-13$ & 4751 & $52.1(51.1-53.1)$ & 131 & $2.8(2.3-3.3)$ \\
\hline $14-15$ & 3043 & $25.7(24.9-26.6)$ & 212 & $6.0(5.2-6.9)$ \\
\hline $16-17$ & 2905 & $22.2(21.4-23.0)$ & 352 & $10.0(9.0-11.2)$ \\
\hline \multicolumn{5}{|l|}{ Gender } \\
\hline Female & 4968 & $47.5(46.5-48.4)$ & 184 & $3.1(2.7-3.6)$ \\
\hline Male & 5731 & $52.5(51.6-53.5)$ & 511 & $7.1(6.5-7.8)$ \\
\hline \multicolumn{5}{|l|}{ Residence } \\
\hline Local & 7551 & $71.7(70.8-72.6)$ & 443 & $4.8(4.3-5.2)$ \\
\hline Non-local & 3148 & $28.3(27.4-29.2)$ & 252 & $6.4(5.6-7.2)$ \\
\hline \multicolumn{5}{|l|}{ Grade point average } \\
\hline Top 25\% & 3367 & $32.5(31.5-33.4)$ & 200 & $4.7(4.1-5.5)$ \\
\hline Average & 5022 & $46.7(45.7-47.7)$ & 254 & $4.0(3.5-4.5)$ \\
\hline Bottom 25\% & 2310 & $20.9(20.1-21.7)$ & 241 & $8.7(7.6-9.8)$ \\
\hline \multicolumn{5}{|l|}{ Type of school } \\
\hline Middle school & 5663 & $62.1(61.2-63.0)$ & 181 & $3.2(2.8-3.7)$ \\
\hline High school & 2185 & $23.9(23.0-24.8)$ & 116 & $5.3(4.4-6.3)$ \\
\hline Vocational high school & 2851 & $14.0(13.5-14.5)$ & 398 & $14(12.7-15.3)$ \\
\hline \multicolumn{5}{|c|}{ Monthly allowance (RMB) } \\
\hline$<200$ & 6225 & $62.1(61.2-63.0)$ & 227 & $3.1(2.7-3.5)$ \\
\hline 200-399 & 1895 & $16.7(16.0-17.4)$ & 140 & $6.1(5.1-7.2)$ \\
\hline $400-599$ & 1001 & $8.5(8.0-9.1)$ & 82 & $6.1(4.8-7.6)$ \\
\hline $600-799$ & 475 & $3.7(3.4-4.1)$ & 51 & $9.1(6.8-12.0)$ \\
\hline 800-999 & 284 & $2.1(1.8-2.3)$ & 35 & $10.9(7.7-15.2)$ \\
\hline$\geq 1000$ & 819 & $6.9(6.4-7.4)$ & 160 & $17.7(15.2-20.5)$ \\
\hline \multicolumn{5}{|l|}{ Morning craving } \\
\hline Never & 10193 & 96.2 (95.8-96.5) & 435 & $3.5(3.2-3.9)$ \\
\hline Rarely & 149 & $1.1(0.9-1.3)$ & 69 & $45.2(36.9-53.8)$ \\
\hline Sometimes & 159 & $1.1(0.9-1.3)$ & 81 & $46.5(38.4-54.8)$ \\
\hline Often & 91 & $0.7(0.6-0.9)$ & 52 & $50.6(39.9-61.4)$ \\
\hline Always & 107 & $0.9(0.8-1.1)$ & 58 & $52.4(42.5-62.1)$ \\
\hline \multicolumn{5}{|l|}{ Ever tobacco use } \\
\hline No & 9598 & $91.6(91.1-92.1)$ & 341 & $3.0(2.7-3.3)$ \\
\hline Yes & 1101 & $8.4(7.9-8.9)$ & 354 & $29.7(26.9-32.6)$ \\
\hline \multicolumn{5}{|l|}{ Parents' smoking } \\
\hline None & 3758 & $36.0(35.0-36.9)$ & 176 & $3.9(3.4-4.6)$ \\
\hline One & 6485 & $59.9(58.9-60.8)$ & 431 & $5.1(4.7-5.7)$ \\
\hline Both & 456 & $4.1(3.8-4.5)$ & 88 & $17.2(14.0-21.0)$ \\
\hline \multicolumn{5}{|l|}{ Friends' smoking } \\
\hline None & 8366 & $82.3(81.6-83)$ & 239 & $2.5(2.2-2.8)$ \\
\hline Some & 2039 & $15.5(14.8-16.1)$ & 312 & $13.8(12.3-15.4)$ \\
\hline Most or all & 294 & $2.2(2.0-2.5)$ & 144 & $47.3(41.3-53.4)$ \\
\hline
\end{tabular}


Table 1. Continued

\begin{tabular}{|c|c|c|c|c|}
\hline \multirow[t]{2}{*}{ Characteristics } & \multicolumn{2}{|c|}{ Overall } & \multicolumn{2}{|c|}{ Ever use of e cigarettes } \\
\hline & n & $\begin{array}{l}\text { Weighted } \% \\
95 \% \text { CI }\end{array}$ & n & $\begin{array}{l}\text { Weighted } \% \\
95 \% \text { CI }\end{array}$ \\
\hline \multicolumn{5}{|c|}{$\begin{array}{l}\text { Exposure to tobacco promotional } \\
\text { advertisement }\end{array}$} \\
\hline No & 4063 & $39.1(38.1-40)$ & 170 & $3.2(2.7-3.7)$ \\
\hline Yes & 6636 & $60.9(60.0-61.9)$ & 525 & $6.5(6.0-7.1)$ \\
\hline \multicolumn{5}{|c|}{$\begin{array}{l}\text { Exposure to tobacco control } \\
\text { advertisement }\end{array}$} \\
\hline No & 979 & $8.8(8.2-9.3)$ & 94 & $8.7(7.1-10.7)$ \\
\hline Yes & 9720 & 91.2 (90.7-91.8) & 601 & $4.9(4.5-5.3)$ \\
\hline \multicolumn{5}{|c|}{ Secondhand smoke } \\
\hline Low exposure & 6118 & $57.4(56.4-58.4)$ & 241 & $3.0(2.6-3.4)$ \\
\hline High exposure & 4581 & $42.6(41.6-43.6)$ & 454 & $8.2(7.4-9.0)$ \\
\hline
\end{tabular}

RMB: Chinese renminbi, $100 \mathrm{RMB}$ about 14 US\$. CI: confidence interval.

Table 2. Correlates of ever e-cigarette use among adolescents stratified by type of school, Shanghai, China, September $2017(\mathrm{~N}=10669)$

\begin{tabular}{|c|c|c|c|}
\hline & $\begin{array}{l}\text { Overall } \\
\text { Crude OR }\left(95^{\circ} \circ \mathrm{CI}\right)^{d}\end{array}$ & $\begin{array}{l}\text { Vocational } \\
\text { Crude OR }\left(95^{\circ} \% \mathrm{CI}\right)^{d}\end{array}$ & $\begin{array}{l}\text { Traditional } \\
\text { Crude OR }\left(95^{\circ} \% \mathrm{CI}\right)^{d}\end{array}$ \\
\hline \multicolumn{4}{|l|}{ Type of school } \\
\hline Vocational vs Traditional & $4.13(3.53-4.82)^{c}$ & $\mathrm{~N} / \mathrm{A}$ & $\mathrm{N} / \mathrm{A}$ \\
\hline \multicolumn{4}{|l|}{ Age (years) } \\
\hline $11-13$ vs $16-17$ & $0.25(0.21-0.31)^{c}$ & $N / A$ & $0.42(0.32-0.56)^{c}$ \\
\hline $14-15$ vs $16-17$ & $0.57(0.47-0.69)^{\mathrm{c}}$ & $0.56(0.45-0.70)^{\mathrm{c}}$ & $0.72(0.53-0.99)^{\mathrm{a}}$ \\
\hline \multicolumn{4}{|l|}{ Gender } \\
\hline Male vs Female & $2.41(2.00-2.89)^{c}$ & $2.58(2.02-3.29)^{c}$ & $2.13(1.66-2.73)^{c}$ \\
\hline \multicolumn{4}{|l|}{ Residence } \\
\hline Non-local vs Local & $1.36(1.15-1.62)^{\mathrm{c}}$ & $1.22(0.98-1.51)$ & $1.24(0.97-1.59)$ \\
\hline Grade point average (cont.) & $1.40(1.24-1.59)^{c}$ & $1.18(1.01-1.39)^{\mathrm{a}}$ & $1.41(1.18-1.68)^{\mathrm{c}}$ \\
\hline Monthly allowance (cont.) & $1.44(1.38-1.51)^{c}$ & $1.23(1.16-1.30)^{\mathrm{c}}$ & $1.45(1.36-1.54)^{c}$ \\
\hline Morning craving (cont.) & $2.92(2.64-3.23)^{\mathrm{c}}$ & $2.91(2.49-3.41)^{c}$ & $2.78(2.47-3.12)^{c}$ \\
\hline \multicolumn{4}{|l|}{ Parents' smoking } \\
\hline One vs None & $1.32(1.09-1.60)^{\mathrm{c}}$ & $1.60(1.24-2.06)^{\mathrm{c}}$ & $1.08(0.84-1.40)^{c}$ \\
\hline Both vs None & $5.05(3.77-6.77)^{c}$ & $3.85(2.53-5.84)^{c}$ & $5.25(3.62-7.62)^{c}$ \\
\hline \multicolumn{4}{|l|}{ Friends' smoking } \\
\hline Some vs None & $6.37(5.28-7.67)^{c}$ & $3.37(2.63-4.32)^{c}$ & $5.93(4.55-7.73)^{c}$ \\
\hline Most or all vs None & $35.66(26.98-47.14)^{\mathrm{c}}$ & $16.36(11.4-23.47)^{c}$ & $37.74(25.74-55.34)^{\mathrm{c}}$ \\
\hline \multicolumn{4}{|l|}{$\begin{array}{l}\text { Exposure to tobacco promotional } \\
\text { advertisement }\end{array}$} \\
\hline Yes vs No & $2.12(1.76-2.57)^{c}$ & $1.39(1.10-1.76)^{b}$ & $2.38(1.81-3.13)^{c}$ \\
\hline \multicolumn{4}{|l|}{$\begin{array}{l}\text { Exposure to tobacco control } \\
\text { advertisement }\end{array}$} \\
\hline Yes vs No & $0.54(0.42-0.68)^{c}$ & $1.03(0.74-1.43)$ & $0.43(0.32-0.59)^{c}$ \\
\hline \multicolumn{4}{|l|}{ Ever tobacco use } \\
\hline Yes vs No & $13.78(11.55-16.46)^{\mathrm{c}}$ & $7.52(6.01-9.40)^{\mathrm{c}}$ & $13.96(10.85-17.94)^{c}$ \\
\hline \multicolumn{4}{|l|}{ Secondhand smoke } \\
\hline High exposure vs Low exposure & $2.87(2.41-3.41)^{c}$ & $2.34(1.89-2.90)^{c}$ & $3.27(2.55-4.20)^{c}$ \\
\hline
\end{tabular}

Cl: confidence interval. OR: odds ratio. a $p<0.05, b p<0.01$, c $p<0.001$. $d$ Data were weighted. 
were significant $(\mathrm{p}<0.001)$. In the adjusted model (Table 3), correlates of e-cigarette use were assessed stratified by school type. For each school type, e-cigarette users were compared against non-users (reference group) on morning craving, parents' and friends' smoking status, knowledge of pro-tobacco advertisements, ever use of tobacco products, and exposure to SHS, controlling for age, gender, GPA, and monthly allowance.

Among students attending vocational schools, ever use of tobacco was the most significant correlate, with ever users having 3.10 (95\% CI: 2.36-4.08) times increased odds of e-cigarette use. Friends' smoking was also a significant correlate, with those reporting most or all of their friends as smokers having 2.97 (95\% CI: 1.84-4.81) times increased odds of e-cigarette use, and those reporting some friends as smokers having 1.68 (95\% CI: 1.25-2.24) times increased odds of e-cigarette use. Odds of e-cigarette use were 1.78 (95\% CI: 1.33-2.36) times higher than for males, 1.73 (95\% CI: 1.01-2.98) times higher for students with both smoking parents, and 1.42 (95\% CI: 1.05-1.91) times higher for those who had knowledge of pro-tobacco advertisements. For each unit increase in morning craving and monthly allowance, odds of e-cigarette use increased by 1.90 (95\% CI: 1.64-2.20) and 1.11 (95\% CI: 1.03-1.18) times, respectively.

Table 3. Correlates of ever e-cigarette use among adolescents stratified by type of school, Shanghai, China, September $2017(\mathrm{~N}=10669)$

\begin{tabular}{|c|c|c|c|}
\hline & $\begin{array}{l}\text { Overall } \\
\text { AOR }\left(95^{\circ} \% \mathrm{CI}\right)^{d}\end{array}$ & $\begin{array}{l}\text { Vocational } \\
\operatorname{AOR}\left(95^{\circ} \% \mathrm{CI}\right)^{d}\end{array}$ & $\begin{array}{l}\text { Traditional } \\
\text { IOR }(95 \% \text { CI })^{d}\end{array}$ \\
\hline \multicolumn{4}{|l|}{ Type of school } \\
\hline Vocational vs Traditional & $1.66(1.32-2.10)^{c}$ & $\mathrm{~N} / \mathrm{A}$ & $\mathrm{N} / \mathrm{A}$ \\
\hline \multicolumn{4}{|l|}{ Age (years) } \\
\hline $11-13$ vs $16-17$ & $0.77(0.58-1.04)$ & N/A & $0.86(0.61-1.21)$ \\
\hline $14-15$ vs $16-17$ & $0.97(0.77-1.22)$ & $0.78(0.61-1.01)$ & $1.14(0.78-1.65)$ \\
\hline \multicolumn{4}{|l|}{ Gender } \\
\hline Male vs Female & $1.91(1.54-2.37)^{\mathrm{c}}$ & $1.78(1.33-2.36)^{\mathrm{c}}$ & $1.99(1.49-2.65)^{\mathrm{c}}$ \\
\hline \multicolumn{4}{|l|}{ Residence } \\
\hline Non-local vs Local & $1.01(0.81-1.26)$ & $0.92(0.70-1.19)$ & $1.07(0.79-1.45)$ \\
\hline Grade point average (cont.) & $1.19(1.04-1.37)^{\mathrm{a}}$ & $1.09(0.92-1.30)$ & $1.24(1.03-1.50)^{\mathrm{a}}$ \\
\hline Monthly allowance (cont.) & $1.14(1.08-1.2)^{c}$ & $1.11(1.03-1.18)^{b}$ & $1.13(1.05-1.23)^{\mathrm{b}}$ \\
\hline Morning Craving (cont.) & $1.68(1.50-1.88)^{c}$ & $1.90(1.64-2.20)^{c}$ & $1.58(1.36-1.83)^{c}$ \\
\hline \multicolumn{4}{|l|}{ Parents' smoking } \\
\hline One vs None & $0.90(0.72-1.13)$ & $1.29(0.96-1.74)$ & $0.77(0.57-1.03)$ \\
\hline Both vs None & $1.72(1.15-2.59)^{b}$ & $1.73(1.01-2.98)^{\mathrm{a}}$ & $1.68(1.01-2.80)^{\mathrm{a}}$ \\
\hline \multicolumn{4}{|l|}{ Friends' smoking } \\
\hline Some vs None & $2.31(1.82-2.95)^{b}$ & $1.68(1.25-2.24)^{b}$ & $2.72(1.97-3.75)^{c}$ \\
\hline Most or all vs None & $4.14(2.78-6.16)^{c}$ & $2.97(1.84-4.81)^{c}$ & $4.87(2.78-8.54)^{c}$ \\
\hline \multicolumn{4}{|l|}{$\begin{array}{l}\text { Exposure to tobacco promotional } \\
\text { advertisement }\end{array}$} \\
\hline Yes vs No & $1.86(1.48-2.35)^{\mathrm{c}}$ & $1.42(1.05-1.91)^{\mathrm{a}}$ & $2.12(1.54-2.91)^{c}$ \\
\hline \multicolumn{4}{|l|}{$\begin{array}{l}\text { Exposure to tobacco control } \\
\text { advertisement }\end{array}$} \\
\hline Yes vs No & $0.79(0.57-1.11)$ & $0.91(0.58-1.42)$ & $0.76(0.49-1.18)$ \\
\hline \multicolumn{4}{|l|}{ Ever tobacco use } \\
\hline Yes vs No & $3.50(2.75-4.45)^{\mathrm{c}}$ & $3.10(2.36-4.08)^{\mathrm{c}}$ & $3.78(2.68-5.34)^{c}$ \\
\hline \multicolumn{4}{|l|}{ Secondhand smoke } \\
\hline High exposure vs Low exposure & $1.68(1.36-2.07)^{c}$ & $1.27(0.98-1.64)$ & $1.93(1.44-2.59)^{\mathrm{c}}$ \\
\hline
\end{tabular}

$\mathrm{Cl}$ : confidence interval. AOR: adjusted odds ratio. a $\mathrm{p}<0.05, \mathrm{~b} p<0.01, \mathrm{c} p<0.001$. $\mathrm{d}$ Data were weighted. 
Among students attending traditional schools, friends' smoking was the most significant correlate, with those reporting most or all of their friends smoking having 4.87 (95\% CI: 2.78-8.54) times increased odds of using e-cigarettes, and those reporting some friends as smokers having 2.72 (95\% CI: 1.97-3.75) times increased odds of using e-cigarettes. Ever use of tobacco was also a significant correlate, with ever users having 3.78 (95\% CI: 2.685.34) times increased odds of e-cigarette use. Odds of e-cigarette use were 2.12 (95\% CI: 1.54-2.91) times higher for those who had seen pro-tobacco advertisements, 1.99 (95\%CI: 1.49-2.65) times greater for males, 1.93 (95\% CI: 1.44-2.59) times greater for students with high exposure to SHS, and 1.68 (95\% CI: 1.01-2.80) times higher for those reporting both parents as smokers. In addition, for each unit increase in morning craving, monthly allowance, or GPA, odds of e-cigarette use increased by 1.58 (95\% CI: 1.36-1.83) times, 1.13 (95\% CI: 1.05-1.23) times, and 1.24 (95\% CI: $1.03-1.50)$ times, respectively.

\section{DISCUSSION}

To our knowledge, this study is one of a limited number examining school-type differences in correlates of e-cigarette use among adolescents in Shanghai, China. We found e-cigarette use more prevalent among students attending vocational rather than traditional schools. However, correlates of e-cigarettes use were similar, regardless of type of school.

Our finding on the higher prevalence of e-cigarette use among students attending vocational schools may be explained by the nature of vocational schools. In China, students at vocational schools often receive less monitoring and discipline from teachers and parents ${ }^{16}$, have significantly lower academic pressure, and enter the workforce directly after graduation. They are more likely to be exposed to social smokers than do students at traditional schools ${ }^{17}$, and their interests can be easily influenced by the so-called 'being cool' culture that involves also smoking ${ }^{18}$. These characteristics may also explain our finding that GPA was a significant correlate of e-cigarette use only among students at traditional instead of vocational schools. More specifically, at traditional schools, students with lower GPAs had higher odds of using e-cigarettes.
Another study, among Finnish adolescents, also found that poor school performance was associated with e-cigarette experimentation ${ }^{19}$. The possible reason could be that those students who do not perform well academically suffer more academic burdens and intense peer competition. Taken together, this evidence implies a need for school-specific e-cigarette control policies. Traditional schools may need to pay more attention to underachieving students and help them reduce stress. Vocational schools may need to invest in helping students to build resilience as a means of avoiding the temptations of e-cigarettes.

Our finding that, regardless of school type, the association between tobacco use and e-cigarette use, as well as morning craving, is consistent with existing findings that e-cigarette use was associated with morning smoking urge ${ }^{20}$ and ever tobacco use $^{11,20}$. No longitudinal study has explored the causal relationship between tobacco and e-cigarette use $^{7}$. Our finding implies that e-cigarette control programs should also include elements targeting tobacco use simultaneously. However, because we did not find a significant association between anti-tobacco advertisements and e-cigarette use, advertisements aimed at curbing the use of tobacco may not be an effective strategy.

Our finding that pro-tobacco advertisements increased odds of e-cigarettes use by 1.72 times, is similar to a study that found exposure to tobacco product advertisements raised e-cigarette awareness ${ }^{11}$. This suggests that those who are aware of or use e-cigarettes may be more attentive to or have greater exposure to tobacco-related messages. Tobacco promotion advertisements may market e-cigarettes as socially attractive, with celebrity endorsement and stylish design, and availability in a wide range of flavors ${ }^{21}$. There is a need to regulate tobacco promotion advertising and promotion concerning e-cigarette marketing.

We also found exposure to SHS increased odds of e-cigarette use among traditional school students, but this correlation was of borderline significance among vocational school students. The newly revised Regulations of Shanghai Municipality on smoking control in public places came into effect on 1 March 2017 and bans smoking in all indoor areas ${ }^{22}$. In spite of this, SHS exposure still remains a serious problem, as we found $42.6 \%$ of respondents had high 
exposure to SHS overall. Another study reported that the prevalence of passive smoking among traditional middle $(67 \%)$ and high $(63.2 \%)$ school students was lower than at vocational schools $(75.6 \%)$ in Shanghai ${ }^{23}$. Given the risks of exposure to SHS and its influence on e-cigarette use, reducing exposure to SHS requires the joint efforts of the whole of society.

We found odds of e-cigarette use were higher among those having more friends as smokers, and this association was more significant among traditional school students. A study among Finnish adolescents ${ }^{19}$ drew similar conclusions that friends were the main source of e-cigarette initiation. Adolescents tend to consider e-cigarettes as attractive, less harmful, and less addictive if their friends are users ${ }^{8}$. Schools are thus recommended to make full use of peer education to disseminate accurate information on e-cigarette use and encourage positive learning. Similarly, consistent with existing studies ${ }^{1}$, we found adolescents whose parents were both smokers had twice the odds of using e-cigarettes. Parents' smoking can have a subtle influence on teenagers ${ }^{24}$; it is possible that living with people who smoke can increase awareness and use of e-cigarettes ${ }^{25}$. Therefore, parents are encouraged to create a smokefree environment at home.

There was also a positive correlation between monthly allowance and odds of e-cigarette use. This finding is consistent with a study among Canadian youth that found having more pocket money was positively associated with e-cigarette use ${ }^{26}$. Pocket money was also associated with cigarette smoking among teenagers ${ }^{27}$. Adolescents with higher monthly allowance have extra money to spend and, thus, can afford e-cigarettes ${ }^{8}$. There is a need for parents and educators to limit and monitor teens' use of their monthly allowance.

\section{Strengths and limitations}

Our study has several limitations. First, due to the cross-sectional design, causal inference cannot be drawn. Longitudinal studies are needed to examine causal relationships between e-cigarette use and its correlates. Second, our study only surveyed adolescents in Shanghai, so our results may not represent all Chinese adolescents. Nonetheless, our study is one of the earliest studies examining this topic. Third, our study only analyzed ever use of e-cigarettes due to a low prevalence rate of current use, thus the degree of severity of e-cigarette use might not be fully captured.

Despite these limitations, our study has important implications for e-cigarette control policies and research. There is a need for joint efforts at the national, school and family level to reduce e-cigarette use among adolescents. At the national level, a study in 2016 identified 68 countries that had existing or new regulations on e-cigarettes; common regulations included restrictions on age-of-purchase, on sales and marketing, and bans on vaping in public places ${ }^{28}$. By introducing rigorous regulations on e-cigarettes, the United Kingdom has kept its use among those aged 11-16 years at $3 \%$ or less ${ }^{6}$. Canada has placed strict regulations on nicotine-containing e-cigarettes ${ }^{26}$, leading to little advertising or marketing in the traditional media ${ }^{7}$. Experience in these countries suggests that implementing regulations on e-cigarettes could be quite effective. We can raise the minimum age to purchase e-cigarettes and other tobacco products to 21 years $^{29}$, and levy excise tax on e-cigarettes. We could also restrict the sales of e-cigarettes ${ }^{9}$, whether containing nicotine or not, and prohibit e-cigarettes from being marketed as smoking cessation aids or sold in a form resembling tobacco products. At the school level, since school is the main place where adolescents gather and receive education, educators play a vital role in guiding adolescents to participate in health promotion activities. In the past decades, China has been committed to carrying out school-based tobacco control programs. But when it comes to e-cigarette use, there is rarely any school-based prevention or intervention program ${ }^{1}$. For example, despite the fact that many e-cigarettes contain the addictive substance nicotine, advertisers have long been promoting e-cigarettes as tobacco-free and harmless, which can lead to increased perceptions of attractiveness among uninformed adolescents. Therefore, adolescents need to be taught how to critically process information contained in advertising. Smoking prevention should not be limited to implementing smoking bans, providing adolescents with knowledge about the impact of smoking on health is also critical, and school is a very good place for such teaching activities. At the family level, parents are responsible for ensuring a smoke-free environment and limiting their teens' monthly allowance. 


\section{CONCLUSIONS}

The use of e-cigarettes among students in traditional schools is lower than in vocational schools. However, correlates of e-cigarettes use were similar regardless of type of school, including poor academic performance, ever tobacco use, morning craving, tobacco promotion advertisement, exposure to secondhand smoke, having friends or parents who smoke, and higher monthly allowance. Reducing e-cigarette use among adolescents requires the joint efforts of schools, families and the whole of society.

\section{REFERENCES}

1. Jiang N, Wang MP, Ho SY, Leung LT, Lam TH. Electronic cigarette use among adolescents: a cross-sectional study in Hong Kong. BMC Public Health. 2016;16. doi:10.1186/s12889-016-2719-4

2. Filippidis FT, Laverty AA, Gerovasili V, Vardavas CI. Twoyear trends and predictors of e-cigarette use in 27 European Union member states. Tob Control. 2017;26(1):98-104. doi:10.1136/tobaccocontrol-2015-052771

3. Kong G, Morean ME, Cavallo DA, Camenga DR, KrishnanSarin S. Reasons for Electronic Cigarette Experimentation and Discontinuation Among Adolescents and Young Adults. Nicotine Tob Res. 2015;17(7):847-854. doi:10.1093/ntr/ntu257

4. Kasza KA, Bansal-Travers M, O’Connor RJ, et al. Cigarette smokers' use of unconventional tobacco products and associations with quitting activity: findings from the ITC4 U.S. cohort. Nicotine Tob Res. 2014;16(6):672-681. doi:10.1093/ntr/ntt212

5. Westling E, Rusby JC, Crowley R, Light JM. Electronic Cigarette Use by Youth: Prevalence, Correlates, and Use Trajectories From Middle to High School. J Adolesc Health. 2017;60(6):660-666. doi:10.1016/j.jadohealth.2016.12.019

6. Bauld L, MacKintosh AM, Eastwood B, et al. Young People's Use of E-Cigarettes across the United Kingdom: Findings from Five Surveys 2015-2017. Int J Environ Res Public Health. 2017;14(9). doi:10.3390/ijerph14090973

7. Hammond D, Reid JL, Cole AG, Leatherdale ST. Electronic cigarette use and smoking initiation among youth: a longitudinal cohort study. CMAJ. 2017;189(43):E1328-E1336. doi:10.1503/cmaj.161002

8. Park S, Lee H, Min S. Factors associated with electronic cigarette use among current cigarette-smoking adolescents in the Republic of Korea. Addict Behav. 2017;69:22-26. doi:10.1016/j.addbeh.2017.01.002

9. Chang HC, Tsai YW, Shiu MN, Wang YT, Chang PY. Elucidating challenges that electronic cigarettes pose to tobacco control in Asia: a population-based national survey in Taiwan. BMJ Open. 2017;7(3). doi:10.1136/bmjopen-2016-014263

10. Jiang N, Chen J, Wang MP, et al. Electronic cigarette awareness and use among adults in Hong Kong. Addict Behav. 2016;52:34-38. doi:10.1016/j.addbeh.2015.08.008

11. Lee JA, Lee S, Cho HJ. The Relation between Frequency of E-Cigarette Use and Frequency and Intensity of Cigarette Smoking among South Korean Adolescents. Int J Environ Res Public Health. 2017;14(3). doi:10.3390/ijerph14030305

12. Xiao L, Parascandola M, Wang C, Jiang Y. Perception and Current Use of E-cigarettes Among Youth in China. Nicotine Tob Res. 2018;21(10). doi:10.1093/ntr/nty145

13. Dutra LM, Glantz SA. E-cigarettes and National Adolescent Cigarette Use: 2004-2014. Pediatrics. 2017;139(2). doi:10.1542/peds.2016-2450

14. Wills TA, Knight R, Williams RJ, Pagano I, Sargent JD. Risk factors for exclusive e-cigarette use and dual e-cigarette use and tobacco use in adolescents. Pediatrics. 2015;135(1):e43-e51. doi:10.1542/peds.2014-0760

15. Wu Q, Yu J, Yang C, et al. Nonmedical Use of Cough Syrup Among Secondary Vocational School Students: A National Survey in China. Medicine. 2016;95(10):e2969. doi:10.1097/md.0000000000002969

16. Aho H, Koivisto AM, Paavilainen E, Joronen K. Parental involvement and adolescent smoking in vocational setting in Finland. Health Promot Int. 2018;33(5):846-857. doi:10.1093/heapro/dax027

17. Wu X. Comparative analysis of levels of awareness about the dangers of tobacco knowledge and smoking status between ordinary high school students and vocational high school students. Chin J of PHM. 2017;33(02):247249

18. Lv YB, Chen T, Xv SS, Chen Y, Huang H. Smoking status and influencing factors among vocational students in Shanghai. Chin J Sch Health. 2012;33(5):521-523.

19. Kinnunen JM, Ollila H, El-Amin SelT, Pere LA, Lindfors PL, Rimpela AH. Awareness and determinants of electronic cigarette use among Finnish adolescents in 2013: a populationbased study. Tob Control. 2015;24(e4):e264-e270. doi:10.1136/tobaccocontrol-2013-051512

20. Wang MP, Ho SY, Leung LT, Lam TH. Electronic cigarette use and its association with smoking in Hong Kong Chinese adolescents. Addict Behav. 2015;50:124127. doi:10.1016/j.addbeh.2015.06.037

21. de Lacy E, Fletcher A, Hewitt G, Murphy S, Moore G. Cross-sectional study examining the prevalence, correlates and sequencing of electronic cigarette and tobacco use among 11-16-year olds in schools in Wales. BMJ Open. 2017;7(2). doi:10.1136/bmjopen-2016-012784

22. Xie LL, Lu CG, Shao XF, Yu X. Analysis of Tobacco Control Effects in Public Places in Qingpu District of Shanghai Before and After the Amendments of Tobacco Control Regulation in Public Places of Shanghai. Health Education and Health Promotion. 2017;12(05):475477+81. doi:10.16117/j.cnki.31-1974/r.201705024

23. Zhu JF, Li N, He YP, Cai Y, Ma J. Status of passive smoking and its relationship with enviromental factors amongmiddle 
school students in Shanghai. Journal of Shanghai Jiaotong University ( Medical Science). 2012;32(07):836-840. doi:10.3969/j.issn.1674-8115.2012.07.004

24. El-Amin SelT, Nwaru BI, Ginawi I, Pisani P, Hakama M. The role of parents, friends and teachers in adolescents' cigarette smoking and tombak dipping in Sudan. Tob Control. 2011;20(2):94-99. doi:10.1136/tc.2010.038091

25. Khoury M, Manlhiot C, Fan CP, et al. Reported electronic cigarette use among adolescents in the Niagara region of Ontario. CMAJ. 2016;188(11):794-800. doi:10.1503/cmaj.151169

26. Czoli CD, Hammond D, Reid JL, Cole AG, Leatherdale ST. Use of Conventional and Alternative Tobacco and Nicotine Products Among a Sample of Canadian Youth. J Adolesc Health. 2015;57(1):123-125. doi:10.1016/j.jadohealth.2015.03.006

27. Cui Y, Forget EL, Zhu Y, Torabi M, Oguzoglu U. The effects of cigarette price and the amount of pocket money on youth smoking initiation and intensity in Canada. Can J Public Health. 2018;110(1). doi:10.17269/s41997-0180123-9

28. Kennedy RD, Awopegba A, De Leon E, Cohen JE. Global approaches to regulating electronic cigarettes. Tob Control. 2017;26(4):440-445. doi:10.1136/tobaccocontrol-2016-053179

29. Spindle TR, Hiler MM, Cooke ME, Eissenberg T, Kendler KS, Dick DM. Electronic cigarette use and uptake of cigarette smoking: A longitudinal examination of U.S. college students. Addict Behav. 2017;67:66-72. doi:10.1016/j.addbeh.2016.12.009
ACKNOWLEDGEMENTS

We thank all the students, their parents, and their schools for participating in this study.

\section{CONFLICTS OF INTEREST}

The authors have completed and submitted the ICMJE Form for Disclosure of Potential Conflicts of Interest and none was reported.

\section{FUNDING}

This work was funded by the National Natural Science Foundation of China (Grant No. 71403169; 2014) and by the Shanghai Key Discipline Construction Project in Public Health (Grant No. 15GWZK1002; 2015).

\section{AUTHORS' CONTRIBUTIONS}

$J Y, Y H$ and $J Z$ were responsible for the research design, wrote the study protocol, prepared materials for the field survey and managed field activities. JZ and QW carried out data analysis and results interpretation. $\mathrm{JL}$ and $\mathrm{OW}$ prepared the manuscript. $\mathrm{OW}$ and $\mathrm{JZ}$ oversaw and revised the manuscript. $\mathrm{JL}$ and $\mathrm{GX}$ were responsible for data collection. All authors read and approved the final manuscript.

\section{PROVENANCE AND PEER REVIEW}

Not commissioned; externally peer reviewed. 